\title{
Reconceptualizing Technology Integration to Meet the Necessity of Transformation
}

\author{
Chris Dede \\ Harvard Graduate School of Education
}

\begin{abstract}
Our society can no longer afford a labor-intensive model of education that uses expensive human resources inefficiently; this is a permanent sea change that has already happened in many other service sectors of our economy. To meet this challenge, we must reconceptualize technology integration not as automating conventional classroom processes - or even as innovating within the structure of industrial era schools - but instead as bridging to ways of teaching/learning so different that integration is no longer an accurate description. The U.S. Department of Education's 2010 National Educational Technology Plan presents an affordable, transformational vision for $21^{\text {st }}$ century education, infusing technology into every aspect of learning in school and out. In classrooms, Digital Teaching Platforms (DTP) seem a promising, scalable approach for attaining personalized instruction with large class sizes. Researchers in learning technologies should develop design-based innovations that support various aspects of the Plan and are practical at scale.
\end{abstract}

We live in a time when the industrial era school system is on the verge of collapse. Our society can no longer afford a labor-intensive model of education that uses expensive human resources inefficiently. With current proposals we may now see student-teacher ratios in some urban settings climbing to an unworkable level of 45, 50, even 60 pupils per class (Dolan, 2011; Dillon, 2011). This may not be a temporary financial dislocation due to an economic downturn, but a permanent sea change that has already happened in every other service sector of our economy. Further, in K-12 schooling, our stellar illustrations of success are based on personal heroism, educators who make sacrifices in every other part of their lives in order to help their students. These are wonderful stories of saint-like dedication, but such a model for educational improvement is unscalable to typical teachers. We have not found a way to be effective and affordable at scale, and our resources are now dwindling rather than growing.

All other professions are successfully transforming to affordable models that use technology to empower typical professionals to be effective. The U.S. Department of Education's 2010 National Educational Technology Plan (NETP) presents a 
transformational vision for $21^{\text {st }}$ century education that builds on insights about modern interactive media gained from other parts of the economy, but also depicts new processes and structures that recognize the unique challenges of helping students learn lifelong and life wide. How can we reconceptualize "technology integration" not as automating conventional classroom processes - or even as innovating within the structure of industrial era schools - but instead as bridging to ways of teaching/learning so different that "integration" is no longer an accurate description?

\section{A Framework for $21^{\text {st }}$ Century Education}

The NETP (USDoEd, 2010) is a rich document that readers can interpret from a variety of perspectives. In this article, the lens I will use is that of redesigning industrialera schooling. I believe that our society should transform its current educational system into a different model better suited to prepare students for the opportunities and challenges of an emerging global, knowledge-based civilization (Dede, 2007). Given the goal of transforming today's schools and colleges to a new $21^{\text {st }}$ century model of formal education that would support people's learning across their entire lifespan, what elements in the Plan are suggestive about foundations for this redesign (Dede, 2010)? The elements of the NETP are listed below and are found in the report Transforming American Education; Learning Powered by Technology (USDoEd, 2010).

\section{Learning}

- Learning can no longer be confined to the years we spend in school or the hours we spend in the classroom: It must be life-long, life-wide, and available on demand. (p. 9)

- Technology provides access to a much wider and more flexible set of learning resources than is available in classrooms and connections to a wider and more flexible set of "educators," including teachers, parents, experts, and mentors outside the classroom. (pp. 11-12)

- Engaging and effective learning experiences can be individualized or differentiated for particular learners (either paced or tailored to fit their learning needs) or personalized, which combines paced and tailored learning with flexibility in content or theme designed to fit the interests and prior experience of each learner. (p. 12) 


\section{Assessment}

- Through multimedia, interactivity, and connectivity it is possible to assess competencies that we believe are important and that are aspects of thinking highlighted in cognitive research. It also is possible to directly assess problemsolving skills; make visible sequences of actions taken by learners in simulated environments; model complex reasoning tasks; and do it all within the contexts of relevant societal issues and problems that people care about in everyday life. ( $p$. 27)

- When students are learning online, there are multiple opportunities to exploit the power of technology for formative assessment. The same technology that supports learning activities gathers data in the course of learning that can be used for assessment... As students work, the system can capture their inputs and collect evidence of their problem-solving sequences, knowledge, and strategy use, as reflected by the information each student selects or inputs, the number of attempts they make, the number of hints and feedback given, and the time allocation across parts of the problem. (pp. 29-30)

\section{Teaching}

- Connected teaching offers a vast array of opportunities to personalize learning. Many simulations and models for use in science, history, and other subject areas are now available online, including immersive virtual and augmented reality environments that encourage students to explore and make meaning in complex simulated situations (Dede, 2009). To deeply engage their students, educators need to know about their students' goals and interests and have knowledge of learning resources and systems that can help students plan sets of learning experiences that are personally meaningful... Although using technology to personalize learning is a boost to effective teaching, teaching is fundamentally a social and emotional enterprise. The most effective educators connect to young people's developing social and emotional core (Ladson-Billings, 2009; Villegas \& Lucas, 2002) by offering opportunities for creativity and self-expression.

Technology provides an assist here as well...Digital authoring tools for creating multimedia projects and online communities for sharing them with the world offer students outlets for social and emotional connections with educators, peers, communities, and the world at large. Educators can encourage students to do this within the context of learning activities, gaining further insights into what 
motivates and engages students-information they can use to encourage students to stay in school. (pp. 41-42)

- All institutions involved in preparing educators should provide technologysupported learning experiences that promote and enable the use of technology to improve learning, assessment, and instructional practices. This will require teacher educators to draw from advances in learning science and technology to change what and how they teach, keeping in mind that everything we now know about how people learn applies to new teachers as well. The same imperatives for teacher preparation apply to ongoing professional learning. Professional learning should support and develop educators' identities as fluent users of advanced technology, creative and collaborative problem solvers, and adaptive, socially aware experts throughout their careers. (p. 44)

\section{Productivity}

- One of the most basic assumptions in our education system is time-based or "seat-time" measures of educational attainment...Time-based measures were appropriate in their day, but they are not now when we know more about how people learn and we have access to technology that can help us accommodate different styles and paces of learning. As we move to online learning and learning that combines classroom and online learning, time-based measures will increasingly frustrate our attempts to provide learning experiences that lead to achievement and the pursuit of postsecondary education that our modern world requires. (p. 68)

- Another basic assumption is the inflexible way we organize students into agedetermined groups, structure separate academic disciplines, organize learning into classes of roughly equal size with all the students in a particular class receiving the same content at the same pace, and keep these groups in place all year. The last decade has seen the emergence of some radically redesigned schools, demonstrating the range of possibilities for structuring education. For example, organizing education around the demonstration of competence rather than seat time opens up a wide range of possibilities. The first school district to win the Baldridge Quality Award, Chugach School District in Alaska, achieved remarkable gains in student outcomes after mobilizing its community to identify the competencies it wanted to see in high school graduates and shifting to a 
performance-based system in which diplomas were awarded on the basis of performance on the district's assessment of those competencies. (pp. 68-69)

- As we seek ways to extend learning time, in addition to considering the amount of time students spend in school, we should also look at whether we can provide engaging and powerful learning experiences through other means. For example, we know that students' lives outside school are filled with technology that gives them 24/7 mobile access to information and resources and allows them to participate in online social networks and communities where people from all over the world share ideas, collaborate, and learn new things. Our education system should leverage students' interest in technology and the time they currently spend learning informally outside the regular school hours to extend learning time in a way that motivates them even more. (pp. 70-71)

In my opinion, these NETP ideas about learning, assessment, teaching, and productivity are most powerful when implemented via a "distributed" model of formal education, in which parents trained and licensed as tutors, informal educators (e.g., museum staff, librarians) certified as coaches, and community members prepared and licensed as mentors are also paid "professional educators" (Dede, 2010). In such a $21^{\text {st }}$ century educational system, schools of education would prepare, license, and provide professional support for teachers, tutors, coaches, and mentors who were trained to orchestrate their coordinated activities through the use of a sophisticated technology infrastructure. Clearly, many aspects of such a transformed system would move beyond "integrating" technology into industrial era classroom structures.

\section{Digital Teaching Platforms}

However, even a $21^{\text {st }}$ century educational system will have custodial responsibilities. Regardless of the educational structure, youth below a certain age (which could be substantially younger now) will spend their days in classrooms under the supervision of a teacher, and adolescents above that age will spend some time in learning environments sheltered from the world and customized for interpretation, and reflection with support from a teacher. Given large class sizes because of economic necessity, what types of technology supports would aid teachers in engaging students, helping them learn academic content, and providing socialization into society?

My colleague John Richards and I are preparing an edited book on Digital Teaching Platforms (Dede \& Richards, in press). The DTP is a category of products 
designed to bring interactive technology to teaching and learning in classrooms; in a DTP, each student and the teacher have laptops, or some equivalent computational device, connected to the network. A full-fledged DTP addresses three major requirements of contemporary classrooms. First, a DTP is a completely realized, networked digital environment that includes interactive interfaces for both teachers and students. Teachers use the administrative tools of this digital environment to create lessons and assignments for students and to manage and evaluate the work the students return. A DTP provides specific tools for assessment: creating tests, assigning them to students, and reviewing the results. The teacher tools also provide timely reports on student progress or their remedial needs. The administrative tools for students allow them to complete assignments and assessments. More important, these tools allow for both individual and group work. Some students can work independently on individualized assignments, while others can work collaboratively on shared assignments. Second, a DTP provides the content of the curriculum and assessments for teaching and learning in digital form. This content includes all of the information in the curriculum, instruction, exercises, and assessments. The content also includes interactive elements, manipulative activities, special-purpose applications, multimedia materials, and so on. Third, a DTP supports real-time, teacher-directed interaction in the classroom. It includes special tools for managing classroom activity; monitoring progress on assignments; displaying student work, demonstrations and challenges on interactive displays; managing group discussions; and coordinating all large-group and small-group activities.

The types of power tools teachers now have for classrooms include (1) media increasing the efficiency and engagement of presentational instruction (e.g., slideshows, clickers, interactive whiteboards) and (2) learning management systems that deliver a limited amount of customized content to students without the need for teacher involvement. Course Delivery Learning Management Systems (LMS) provide both the content of the course and the platform for instruction (Richards \& Walters, in press). The LMS has both teacher and student accounts. The system assigns work to students, creates and assigns tests, and reviews the results. These systems provide all the content needed for the course: instructional content, exercise assignments, and test questions. They often provide elaborate multimedia elements as well. The tight linkage between learning and assessment can be richly exploited in computer-based products, as shown in Figure 1. 


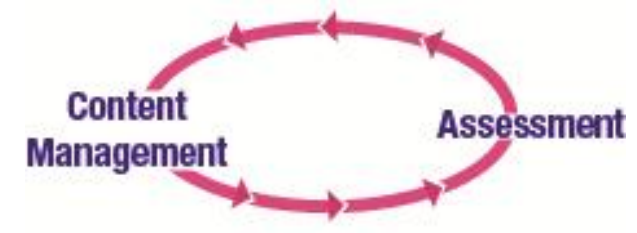

Figure 1. LMS

In contrast, DTPs provide the closed assess-teach feedback loop that helps with practice and personalization, but they also include a second feedback loop that flows through the teacher in the typical interactions in a normal classroom. The teacher evaluates student responses and makes prescriptive decisions about each student based on that evaluation. The DTP accommodates personalization through the inner loop and open-ended explorations through the teacher, as shown in Figure 2.

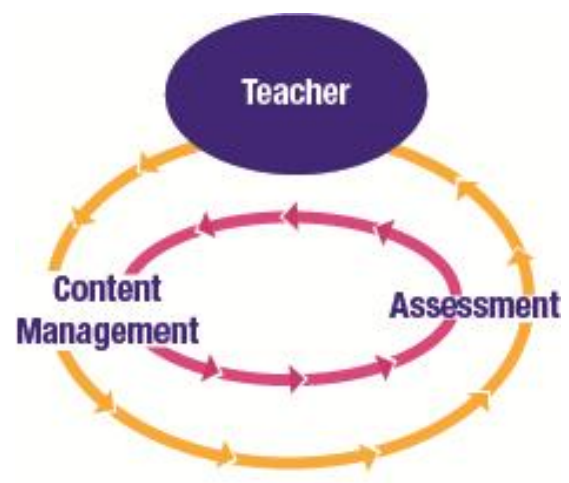

Figure 2. DTP

The important difference between DTPs and LMSs is that, with the former, the teacher - not the technology - is the center of instruction (Dede \& Richards, in press). The teacher can shift quickly from large group demonstrations, to small group activities, to individualized practice and assessment. Students move seamlessly from using their devices for some of these activities to closing their computers and participating in discussions. The teacher is fully in control of student activities by making assignments, mentoring individuals, and leading discussions. In DTPs, the pedagogy of the curriculum is designed using principles of guided social constructivism as a theory of learning and the system provides the support for a transformation of teaching and learning. 
As discussed earlier, financial exigencies are driving up class sizes. Without the power of DTPs to assist them, educators cannot succeed with high ratios of students to instructor. In contrast, with DTPs coupled to the transformational models discussed in the NETP, we can envision an effective, affordable 21st century educational system. What then are the challenges of developing the types of learning experiences DTPs can enable and of integrating these experiences into such a learning infrastructure?

\section{Technology "Integration" for the $21^{\text {st }}$ Century}

As scholars, many of us design technology-based innovations to aid learning in classrooms, working to ensure that teachers can integrate these without too much difficulty. We study barriers to technology integration and provide supports that help teachers overcome those difficulties. In the past, this has been useful; at this point in history, however, I believe this process of research-based educational improvement should change in two key respects.

First, we should design our innovations to be implemented within the larger context of Digital Teaching Platforms (or some other type of comprehensive curriculum/assessment system). Piecemeal improvements are no longer adequate to meet the challenges of education for the $21^{\text {st }}$ century, nor can educators be expected to cobble together overall instructional strategies by aggregating and integrating isolated contributions from scholars. Our interventions need not be comprehensive, but they should be designed to easily fit into larger infrastructures for curriculum and assessment that vendors deliver. This means that our improvements should include the rich integration of teaching and assessment characteristic of DTPs, as well as some instruction delivered and scored by technology to complement what the teacher does. The latter is essential in a time of limited resources.

Second, we need to design innovations that are scalable to large numbers of students and teachers across a range of contexts. "Boutique" interventions that work only under ideal conditions for success (skilled teachers, motivated and well prepared students, special resources) are useful for theoretical development, and I am not arguing against these as a form of scholarly activity. However, large-scale educational improvement requires more than innovations that work only in unusual circumstances and advances in theory; we must design and validate interventions that work at scale under a variety of adverse circumstances. Only this type of innovation will result in widespread usage of technology to empower learning and teaching. 


\section{Designing for Scale}

In the context of innovations in teaching/curriculum, Coburn (2003) defines scale as encompassing four interrelated dimensions: depth, sustainability, spread, and shift in reform ownership. Depth refers to deep and consequential change in classroom practice, altering teachers' beliefs, norms of social interaction, and pedagogical principles as enacted in the curriculum. Sustainability involves maintaining these consequential changes over substantial periods of time, and spread is based on the diffusion of the innovation to large numbers of classrooms and schools. During shift, districts, schools, and teachers assume ownership of the innovation, deepening, sustaining, and spreading its impacts. My colleagues and I (Dede, Honan, \& Peters, 2005) proposed a fifth dimension, evolution, to extend Coburn's framework. The adopters of an innovation revise it and adapt it in such a way that it is influential in reshaping the thinking of its designers. This in turn creates a community of practice between adopters and designers whereby the innovation evolves.

Viewing the process of scaling from a design perspective suggests various types of activities to achieve scale along each dimension (Clarke \& Dede, 2009):

- Depth: evaluation and research (design-based research) to understand and enhance causes of effectiveness

- Sustainability: robust-design to enable adapting to inhospitable contexts

- Spread: modifying to retain effectiveness while reducing resources and expertise required

- Shift: moving beyond "brand" to support users as co-evaluators, co-designers, and co-scalers

- Evolution: learning from users' adaptations to rethink the innovation's design model

These dimensions do not describe a linear progression through phases, but instead delineate various types of processes developers can use to help take an innovation to scale. These developmental processes are interrelated in complex ways; for example, sustainability is fostered by spread, and evolution is accelerated by shift. While all dimensions of scale are important for achieving technology integration in $21^{\text {st }}$ century classrooms, for reasons of length I will focus only on the dimension of sustainability. 
Design for sustainability centers on the issue of contextual variation and involves designing educational innovations to function effectively across a range of relatively inhospitable settings (Dede, 2006). This is in contrast to models for effective transfer of an innovation to another context that involve partnering with a particular school or district to make that setting a conducive site for adapting a particular design. Transferring innovation into typical school sites that are not partners necessitates developing interventions that are "ruggedized" to retain substantial efficacy in relatively barren contexts, in which some conditions for success are absent or attenuated. Under these circumstances, major aspects of an innovation's design may not be enacted as intended by its developers.

One would not expect that interventions created for use in multiple settings through robust-design strategies will outperform an intervention designed for specific classrooms that have all the necessary conditions for success. For example, while apples are versatile fruit, pomologists need to adapt the design of an orchard, cultivar, and irrigation practices in order to grow apples in climates that are harsher and have shorter seasons. They would not expect these cultivars to yield more fruit than orchards in climates that have evolved for more ideal conditions. The strengths of ruggedized interventions are likely weaknesses under better circumstances; for example, high levels of support for learner help and engagement that aid unengaged pupils with low prior preparation could be intrusive overhead for better-prepared, already motivated students.

Too often, as scholars we stop with the dimension of depth in designing and implementing our innovations. Starting with depth and proving our interventions are worthy of being scaled is very important. However, declaring victory at that point and expecting teachers to integrate our improvements is premature - to transform practice, we then need to design for and demonstrate the sustainability of our innovations. The challenge of attaining sustainability (and spread, shift, evolution) often helps to differentiate between research insights that truly can help our educational system meet the challenges of the $21^{\text {st }}$ century and scholarly activities that, while valuable for theory and for special circumstances, are intrinsically unscalable and cannot lead to widely adapted improvements in teaching and learning.

\section{Conclusion}

I have argued that a new definition and process of technology integration are central for $21^{\text {st }}$ century education. Due to financial problems that may be a permanent 
shift in K-12 schooling, student-teacher ratios are climbing to levels unworkable for even the best conventional instruction. We cannot solve this problem at scale by the personal heroism of individual teachers, but instead must find technology-based strategies effective for classroom teaching and learning with large numbers of pupils. The 2010 National Educational Technology Plan presents such a vision of $21^{\text {st }}$ century education, in which technology is infused into every process to improve effectiveness. Achieving this vision requires reconceptualizing technology integration not as automating conventional classroom processes - or even as innovating within the structure of industrial era schools - but instead as bridging to ways of teaching/learning so different that integration is no longer an accurate description.

The Plan focuses on creating formal educational systems in which substantial amounts of learning take place outside classroom situations. Even in such a transformed $21^{\text {st }}$ century structure, for a variety of reasons classroom instruction will continue to be crucial. Integration in these circumstances will involve designing and validating technology supports that aid teachers in engaging students, helping them learn academic content, and providing socialization into society, even under conditions of high student-teacher ratios. Providing teachers with "power tools," such as DTPs or some other type of comprehensive curricular technology infrastructure, is essential for achieving this.

Such a shift in educational structures and resources has two major implications for research-based improvement efforts. First, we should design our innovations to be implemented within the larger context of DTP (or some other type of comprehensive curriculum and assessment system). This means the interventions we develop and study should include the rich integration of teaching and assessment characteristic of DTPs, as well as some instruction delivered and scored by technology to complement what the teacher does.

Second, we should design innovations that are scalable to large numbers of students and teachers across a range of contexts, including a variety of adverse circumstances that do not include the ideal conditions for success. Designing for scale involves thinking along five dimensions (depth, sustainability, spread, shift, and evolution). Moving beyond designs and studies that focus on depth to then achieve these other dimensions in our innovations is crucial to developing widely adapted improvements in teaching and learning that can meet the challenges of the $21^{\text {st }}$ century. This is the type of technology integration on which we in a field should focus. 


\section{References}

Clarke, J., \& Dede, C. (2009). Design for scalability: A case study of the River City curriculum. Journal of Science Education and Technology, 18(4), 353-365. CrossRef GS SEARCH

Coburn, C. E. (2003). Rethinking scale: Moving beyond numbers to deep and lasting change. Educational Researcher, 32(6), 3-12. CrossRef GS SEARCH

Dede, C. (2006). Scaling up: Evolving innovations beyond ideal settings to challenging contexts of practice. In R. K. Sawyer (Ed.), Cambridge handbook of the learning sciences, (pp. 551-566). Cambridge, England: Cambridge University Press. GS SEARCH

Dede, C. (2007). Reinventing the role of information and communications technologies in education. In L. Smolin, K. Lawless, \& N. Burbules (Eds.), Information and communication technologies: Considerations of current practice for teachers and teacher educators [NSSE Yearbook 2007 (106:2)], (pp. 11-38). Malden, MA: Blackwell Publishing. GS SEARCH

Dede, C. (2009). Immersive interfaces for engagement and learning. Science, 323(5910), 66-69. $\underline{\text { CrossRef GS SEARCH }}$

Dede, C. (2010). Reflections on the draft National Educational Technology Plan 2010: Foundations for transformation. Educational Technology 50(6), 18-22. GS SEARCH

Dede, C., Honan, J., \& Peters, L. (Eds.). (2005). Scaling up success: Lessons learned from technology-based educational innovation. New York: Jossey-Bass. GS SEARCH

Dede, C. \& Richards, J. (Eds.). (in press). Digital teaching platforms. New York: Teacher's College Press.

Dillon, S. (2011). Tight budgets mean squeeze in classrooms. New York Times (March 6). Downloaded on April 16, 2011 from http://www.nytimes.com/2011/03/07/education/07classrooms.html? r=1\&pagewa nted=print

Dolan, M. (2011). Detroit schools cuts plan approved. Wall Street Journal (February 22). Downloaded on April 16, 2011 from http://online.wsj.com/article/SB1000142405274870361060457615878351344521 $\underline{\text { 2.html }}$ 
Ladson-Billings, G. (2009). The dreamkeepers: Successful teachers of African American children. San Francisco: Wiley. GS SEARCH

Richards, J., \& Walters, J. (in press). The digital teaching platform in the spectrum of educational technologies. In C. Dede \& J. Richards (Eds.), Digital teaching platforms. New York: Teacher's College Press.

U.S. Department of Education (USDoEd). (2010). Transforming American education: Learning powered by technology [National Educational Technology Plan 2010]. Washington, DC: Office of Educational Technology, U.S. Department of Education. VIEW ITEM

Villegas, A. M., \& Lucas, T. (2002). Preparing culturally responsive teachers. Journal of Teacher Education, 53(1), 20-32. CrossRef GS SEARCH

\section{About the Author}

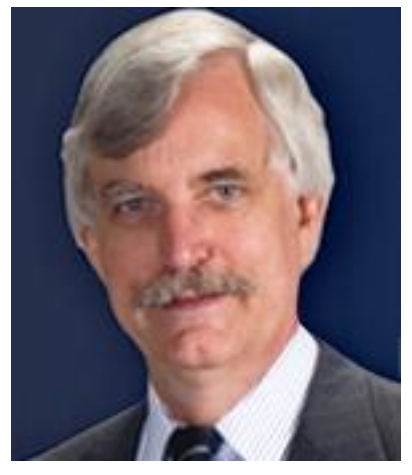

Chris Dede is the Timothy E. Wirth Professor in Learning Technologies at Harvard's Graduate School of Education. His fields of scholarship include emerging technologies, policy, and leadership. His funded research includes four grants from NSF and the US Department of Education Institute of Education Sciences to explore immersive simulations and transformed social interactions as means of student engagement, learning, and assessment. In 2007, he was honored by Harvard University as an outstanding teacher, and in 2011 he was named a Fellow of the American Educational Research Association.

Chris has served as a member of the National Academy of Sciences Committee on Foundations of Educational and Psychological Assessment and a member of the 2010 National Educational Technology Plan Technical Working Group. He serves on Advisory Boards and Commissions for PBS TeacherLine, the Partnership for $21^{\text {st }}$ Century Skills, the Pittsburgh Science of Learning Center, and several federal research grants. His co-edited book, Scaling Up Success: Lessons Learned from Technology-based Educational Improvement, was published by Jossey-Bass in 2005. A second volume he edited ${ }_{2}$ Online Professional Development for Teachers: Emerging Models and Methods, was published by the Harvard Education Press in 2006. His latest book, Digital Teaching Platforms, will be published by Teachers College Press in 2012. Email: chris_dede@harvard.edu 